\title{
A RANDOMIZED EVALUATION OF THE REVERSAL OF KETAMINE BY PHYSOSTIGMINE
}

\author{
John C. Drummond, John Brebner, Samuel Galloon and Patricia S. Young
}

THE USE OF KETAMINE HYDROCHLORIDE (Ketalar, $\mathrm{CI}-58$ ) in adult anaesthetic practice has been limited by emergence reactions. ${ }^{1-8}$ Ketamine has several useful clinical attributes including ease of administration, rapid onset of action, partial preservation of laryngo-pharyngeal reflexes, ${ }^{9}$ profound somatic analgesia, ${ }^{10}$ short duration of effect, suitability for asthmatic patients, ${ }^{11.12}$ mild to moderate cardiovascular stimulation and increased uterine tone. ${ }^{13}$ However, the postoperative occurrence of delirium, illusions, hallucinations and vivid frequently unpleasant dreams has reduced the acceptability of ketamine anaesthesia in the eyes of patients, anaesthetists and recovery room personnel.

There have been numerous attempts to ameliorate the undesirable postoperative psychic phenomena, both pharmacologically ${ }^{3.5,6.14-17}$ and by control of sensory input during emergence. ${ }^{18}$ No regimen has proven conspicuously successful. The efficacy of the tertiary amine cholinesterase inhibitor physostigmine salicylate in the reversal of the somnolence and delirium caused by numerous drugs has been established. ${ }^{19}$ An isolated report of the successful reversal of ketamine sedation with physostigmine appeared in 1976. Balmer, ${ }^{20}$ in an apparently small series, observed rapid awakening of volunteers and patients rendered unconscious by an infusion of ketamine. His study did not involve a control series and the dose of ketamine and the dose, time and route of administration of physostigmine were not specified.

This report of Balmer together with suggestive data from animal studies ${ }^{21.22}$ prompted us to undertake a prospective controlled double-blind trial of the reversal of ketamine effects with physostigmine. We have evaluated the influence of intravenous physostigmine administered postoperatively on the time course of recovery of orientation and consciousness and on the occurrence of psychic sequelae following ketamine anaesthesia for a brief gynaecologic procedure.

John C. Drummond, M.D.. John Brebner, M.D., Ph.D., F.R.C.P.(C), Samuel Galloon, M.B., CH.B., F.F.A.R.C.S. Patricia S. Young, R.N. The Department of Anaesthesia, University of Toronto and Toronto General Hospital.

Canad. Anaesth. Soc. J., vol. 26, no. 4. July 1979

\section{Methods}

One hundred and eleven patients between the ages of 18 and 35 undergoing therapeutic abortion by dilatation and suction curettage, were studied. Patients who gave a history of a seizure disorder, cardiovascular disease, psychiatric illness, recent ingestion of sedative, hypnotic or psychoactive drugs and patients not speaking English or French were excluded. Consent was obtained from all patients although no mention was made of dreams or other psychic phenomena. The protocol was approved by the human experimentation committee of the University of Toronto.

Each patient received weight-adjusted premedication with Pantopon and atropine approximately 90 minutes preoperatively (Table I). Induction and maintenance of anaesthesia were achieved by a standard initial dose of ketamine. $2 \mathrm{mg} \cdot \mathrm{kg}^{-1}$, administered intravenously over 40 to 60 seconds, and increments of $0.5 \mathrm{mg} \cdot \mathrm{kg}^{-1}$ as required by patient response. Patients breathed room air. In eighty-four patients (Group A), physostigmine $\left(50 \mu \mathrm{g} \cdot \mathbf{k g}^{-1}\right)$ or a saline bolus was administered intravenously on a random basis in the operating room upon conclusion of the procedure. The dose of physostigmine administered is within the range quoted by Greene, ${ }^{23}$ although it some what exceeds that normally employed in our hospital. ${ }^{24}$ The dose was established by means of a pilot study. Immediately after physostigmine administration the patient was transported to the recovery room. An observer (J.C.D.) who was not present at the conclusion of the procedure assessed the patient's level of consciousness and orientation upon arrival in the recovery room and $5,10,20,30,45$ and 60 minutes thereafter. For the purposes of recording recovery status, six stages of level of consciousness and five stages of orientation were defined (Table II). Patients received routine postoperative nursing care and evaluation and no measures to reduce afferent stimuli were employed. While in the recovery room, patients were observed continuously and any instance of emergence reactions in the form of apparent hallucinations or restlessness re288 
TABLE I

Premedication

\begin{tabular}{lcc}
\hline Weight (kg) & Pantopon (mg) & Atropine (mg) \\
\hline $45-54.9$ & 10 & 0.3 \\
$55-64.9$ & 15 & 0.4 \\
$65-74.9$ & 20 & 0.6 \\
75 & 25 & 0.6 \\
\hline
\end{tabular}

TABLE $\Pi$

Criteria for Recovery Room Staging

Level of Consciousness

Stage I Comatose. Unresponsive to physical or verbal stimuli.

Stage II Responds to physical stimuli. No or nonspecific response to verbal stimuli. Does not respond accurately to questions or commands.

Stage III Purposefully responsive to verbal stimuli, but difficult to rouse requiring repeated or loud commands.

Stage IV Sleeps if undisturbed but rouses readily.

Stage $V$ Awake. Eyes open more than 50 per cent of the time and/or speaks spontaneously.

Stage VI Fully awake.

Orientation

Stage I Disoriented to person, place and time and or behaviour uncontrollable.

Stage II As in Stage I, but can be settled when reassured.

Stage III Oriented to person only.

Stage IV Oriented to person plus place or time.

Stage $V$ Oriented to time, place and person.

TABLE III

Criteria for Recovery Room Discharge

1. Minimum of 60 minutes.

2. Minimum of 30 minutes after any drug administration.

3. Vital signs within preoperative limits.

4. Vital signs stable for 30 minutes.

5. Awake and oriented to within preoperative limits.

was the occurrence of vomiting. Anti-emetics were administered only in the event of persistent emesis. The duration of the recovery room stay was recorded. Time of discharge from the recovery room was determined by the nursing staff in accordance with the criteria applied to all inpatients who have undergone general anaesthesia (Table III).

It has been demonstrated in experimental hyoscine intoxication that the effectiveness of physostigmine as an antidote is enhanced by an increased time interval prior to physostigmine administration. ${ }^{26}$ Accordingly, to assess the importance of an increased interval between the administration of ketamine and physostigmine. a further 27 patients were studied (Group B). Group B patients received physostigmine/placebo 30 minutes after the last dose of ketamine. Premedication, induction and maintenance were accomplished in the same manner as Group $A$. Upon conclusion of the procedure, the patient was transported to the recovery room where an initial assessment of consciousness and orientation was made. The assessment was next performed 30 minutes after the last dose of ketamine and immediately prior to administering the physostigmine/placebo. The physostigmine/ placebo was administered by the recovery room observer from a syringe prepared in the operating room and labeled with the patient's name only. Assessments were repeated at $5,10,20,30,45$ and 60 minutes following administration.

On the morning of the day following anaesthesia, a verbal questionnaire was administered by a nurse (P.Y.) experienced with the administration of postoperative questionnaires but unacquainted with the operative or recovery room course. Seventy-nine of 84 patients in Group $A$ and 24 of 27 patients in Group $B$ were accessible postoperatively. The questionnaire sought to identify aspects of the post-anaesthesia course which are known or might be expected to affect patient acceptance of an anaesthetic technique. Specific questions concerning the occurrence and nature of dreams and the occurrence of nausea. vomiting and dizziness were posed.

Level of Consciousness and Orientation scores were treated arithmetically in generating average scores for the various populations at a given time. Statistical analysis of these scores was done by a non-parametric test (Chi square). All other statistical analysis was done by an unpaired t-test. Significance is taken as proven when $p<0.05$.

\section{Results}

There were no significant differences between the physostigmine and placebo populations of either group in terms of age and weight, or variables related to anaesthesia and operation, i.e. number of doses, total dose of ketamine and duration of procedure (Table IV).

\section{Level of Consciousness, Oriemtation and Recovery Room Time}

The recovery room data do not demonstrate 
TABLE IV

Patient and Anaesthetic Data

\begin{tabular}{|c|c|c|c|c|}
\hline & \multicolumn{2}{|c|}{ Group A } & \multicolumn{2}{|c|}{ Group B } \\
\hline & $\begin{array}{c}\text { Physostigmine } \\
n=40\end{array}$ & $\begin{array}{l}\text { Placebo } \\
n=44\end{array}$ & $\begin{array}{c}\text { Physostigmine } \\
n=14\end{array}$ & $\begin{array}{l}\text { Placebo } \\
\mathbf{n}=13\end{array}$ \\
\hline $\begin{array}{l}\text { Weight (kg) } \\
\text { Age (yr) }\end{array}$ & $\begin{array}{l}59.9 \pm 13.2 \\
23.3 \pm 4.1\end{array}$ & $\begin{array}{l}57.5 \pm 10.7 \text { n.s. } \\
23.2 \pm 4.1 \text { n.s. }\end{array}$ & $\begin{array}{l}62.5 \pm 8.3 \\
24.8 \pm 5.2\end{array}$ & $\begin{array}{l}58.6 \pm 9.2 \text { n.s.* } \\
24.9 \pm 4.6 \text { n.s. }\end{array}$ \\
\hline $\begin{array}{l}\text { No. of doses } \\
\text { Total dose }\left(\mathrm{mg} \cdot \mathrm{kg}^{-1}\right)\end{array}$ & $\begin{array}{l}2.1 \pm 1.1 \\
2.5 \pm 0.5\end{array}$ & $\begin{array}{l}2.3 \pm 1.3 \text { n.s. } \\
2.7 \pm 0.7 \text { n.s. }\end{array}$ & $\begin{array}{l}2.2 \pm 1.9 \\
2.6 \pm 0.9\end{array}$ & $\begin{array}{l}2.1 \pm 1.1 \text { n.s. } \\
2.5 \pm 0.5 \text { n.s. }\end{array}$ \\
\hline Duration (min) & $10.2 \pm 4.0$ & $10.0 \pm 3.3 \mathrm{n.s}$. & $10.6 \pm 4.7$ & $10.0 \pm 3.8 \mathrm{n.s}$. \\
\hline
\end{tabular}

-n.s: Difference not statistically significant.

TABLE $V$

ReCovery ROOM DATA: Group A

\begin{tabular}{lrcl}
\hline \hline & $\begin{array}{c}\text { Physostigmine } \\
\mathbf{n}=\mathbf{4 0}\end{array}$ & $\begin{array}{c}\text { Placebo } \\
\mathbf{n}=44\end{array}$ & \\
\hline L.O.C. on RR arrival & $1.9 \pm 0.9$ & $2.5 \pm 0.8$ & $\mathbf{p}<\mathbf{0 . 0 2 5}$ \\
Orient. on RR arrival & $1.3 \pm 0.8$ & $2.1 \pm 1.4$ & $\mathbf{p}<\mathbf{0 . 0 0 5}$ \\
Time to L.O.C. IV & $31.5 \pm 23.1$ & $20.6 \pm 17.6$ & $\mathbf{p}<\mathbf{0 . 0 2}$ \\
Time to L.O.C.V & $54.0 \pm 21.2$ & $45.1 \pm 22.0$ & $\mathbf{n . s .}$ \\
Time to Orient. V & $36.8 \pm 24.7$ & $24.2 \pm 20.6$ & $\mathbf{p}<\mathbf{0 . 0 0 5}$ \\
R.R. time (min) & $101.9 \pm \mathbf{3 2 . 0}$ & $\mathbf{8 1 . 3} \pm 24.6$ & $\mathbf{p}<0.005$ \\
\hline
\end{tabular}

Group A: Physostigmine/placebo in operating room at end of procedure.

any improvement in the immediate postanaesthesia course of patients who received physostigmine salicylate. The results (Table $V$ ) for Group A (physostigmine/placebo at the conclusion of the procedure) in fact reveal a significantly poorer level of consciousness and orientation status on arrival in the recovery room for patients who received physostigmine salicylate $(p<0.025)$. The better status of the placebo group was maintained throughout the recoveryroom course. The mean time to Stage IV wakefulness ("rouses readily") was 31.5 minutes (S.D. $=23.1)$ in the physostigmine group and 20.5 minutes (S.D. $=17.6)$ in the placebo group. The difference is significant $(p<0.02)$. The mean time to Stage $\mathrm{V}$ orientation (time, place and person) was 36.9 minutes (S.D. $=24.7$ ) in the physostigmine group and 24.2 minutes (S.D $=20.6$ ) in the placebo group ( $p<0.02$ ). The physostigmine group in addition required significantly longer periods to achieve recovery-room discharge status, 101.9 minutes (S.D. $=32.0$ ) as compared with 81.3 (S.D = 24.6) for controls $(p<0.005)$.

The results for Group B patients (physostigmine salicylate 30 minutes after last ketamine) are shown in Table VI. There were no significant differences between the physostigmine and placebo groups in terms of level of consciousness and orientation either upon arrival in the reovery room or immediately before the administration of physostigmine/placebo. Nor did inter-group differences in level of consciousness and orientation, as measured by our criteria, develop subsequent to physostigmine/placebo administration. Subtle and transient changes in sensorium were noted in four of the Group $B$ patients who received physostigmine salicylate. These changes were brief and beyand the sensitivity of our staging (Table II). The total recovery room time was greater, however, for the physostigmine group, (116 minutes, S.D. $=35.5$ ), than for the placebo group (84.1 minutes, S.D. $=24.3)(p<$ $0.02)$. The difference in recovery-room time would appear to be out of keeping with the lack of significant difference between level of consciousness and orientation status of the two populations. It is explained by an increased incidence of emesis and the consequent use of antiemetic drugs in the physostigmine population. Recovery-room discharge criteria (Table III) require that a patient remain a minimum of $\mathbf{3 0}$ minutes after drug administration.

Emergence Reactions. The physostigmine and placebo populations did not show significant dif- 
TABLE VI

ReCOVERY ROOM DATA: Group B

\begin{tabular}{lrrrl}
\hline & $\begin{array}{c}\text { Physostigmine } \\
\mathrm{n}=14\end{array}$ & $\begin{array}{c}\text { Placebo } \\
n=13\end{array}$ & \\
\hline L.O.C. on RR arrival & $2.9 \pm 0.6$ & $2.5 \pm 0.9$ & n.s. \\
pre-drug & $3.8 \pm 0.7$ & $4.1 \pm 1.0$ & n.s. \\
at 30 min. & $4.5 \pm 0.5$ & $5.0 \pm 0.9$ & n.s. \\
Orient. on RR arrival & $2.5 \pm 1.5$ & $2.5 \pm 1.8$ & n.s. \\
pre-drug & $4.7 \pm 0.6$ & $4.4 \pm 1.5$ & n.s. \\
at 30 min. & $5.0 \pm 0.0$ & $5.0 \pm 0.0$ & n.s. \\
RR time (min) & $116.0 \pm 35.5$ & $\mathbf{8 4 . 1 \pm 2 4 . 3}$ & p <0.2 \\
\hline
\end{tabular}

Group B: Physostigmine/placebo in recovery room 30 minutes after last ketamine.

L.O.C.: Level of consciousness Orient. = Orientation.

n.s. : Difference not statistically significant.

TABLE VII

Emergence Reactions; Halluctnations and/or Restlessness

\begin{tabular}{|c|c|c|c|c|c|c|c|c|}
\hline & \multicolumn{3}{|c|}{ Group A } & \multicolumn{3}{|c|}{ Group B } & & \\
\hline & $\begin{array}{c}\text { PS } \\
n=40\end{array}$ & $\begin{array}{l}\text { Place } \\
\mathbf{n}=\end{array}$ & & $\begin{array}{c}\text { PS } \\
\mathbf{n}=14\end{array}$ & $\begin{array}{c}\text { Place } \\
n=\end{array}$ & & \multicolumn{2}{|c|}{$\begin{array}{c}\text { Combined } \\
n=111\end{array}$} \\
\hline \multicolumn{9}{|l|}{ Emergence Reactions } \\
\hline Hallucinations (\%) & 8 & 14 & n.s. & 0 & 0 & n.s. & 8 & n.s. \\
\hline Restlessness $(\%)$ & 20 & 14 & n.s. & 29 & 15 & n.s. & 18 & n.s. \\
\hline Overall (\%) & 25 & 23 & n.s. & 29 & 15 & n.s. & 23 & п.5. \\
\hline
\end{tabular}

PS: Physostigmine Salicylate.

n.s.: Difference not statistically significant.

TABLE VIII

Data From POstoperative Questionnaire

\begin{tabular}{|c|c|c|c|c|c|c|c|c|}
\hline & \multicolumn{3}{|c|}{ Group A } & \multicolumn{3}{|c|}{ Group B } & \multirow{2}{*}{\multicolumn{2}{|c|}{$\begin{array}{c}\text { Combined } \\
n=104\end{array}$}} \\
\hline & $\begin{array}{c}\text { PS } \\
\mathbf{n}=37\end{array}$ & $\begin{array}{c}\text { Place } \\
\mathbf{n}=\end{array}$ & & $\begin{array}{c}\text { PS } \\
\mathbf{n}=13\end{array}$ & $\begin{array}{c}\text { Place } \\
\mathbf{n}=\end{array}$ & & & \\
\hline $\begin{array}{l}\text { Dreams (\%) } \\
\text { Unpleasant Dreams (\%) } \\
\text { Nausea }(\%) \\
\text { Vomiting }(\%) \\
\text { Dizziness }(\%)\end{array}$ & $\begin{array}{l}62 \\
38 \\
86 \\
89 \\
70\end{array}$ & $\begin{array}{l}64 \\
29 \\
79 \\
74 \\
60\end{array}$ & $\begin{array}{l}\text { n.s. } \\
\text { n.s. } \\
\text { n.s. } \\
\text { n.s. } \\
\text { n.s. }\end{array}$ & $\begin{array}{l}67 \\
50 \\
92 \\
83 \\
58\end{array}$ & $\begin{array}{l}75 \\
17 \\
75 \\
73 \\
83\end{array}$ & $\begin{array}{l}\text { n.s. } \\
\text { n.s. } \\
\text { n.s. } \\
\text { n.s. } \\
\text { n.s. }\end{array}$ & $\begin{array}{l}65 \\
33 \\
83 \\
82 \\
66\end{array}$ & $\begin{array}{l}\text { n.s. } \\
\text { n.s. } \\
\text { n.s. } \\
\text { n.s. } \\
\text { n.s. }\end{array}$ \\
\hline
\end{tabular}

PS: Phyşostigmine Salicylate.

ת.s.: Difference not statistically significant.

ferences in the occurrence of emergence reactions in the form of hallucinations or restlessness (Table VII). In Group A, apparent hallucinations were observed in 8 per cent (3/40) of patients who received physostigmine and in 14 per cent (6/44) of those who received placebo. No hallucinations were observed in Group B patients. Restlessness requiring intervention in the form of restraint or reassurance occurred in 20 per cent $(8 / 40)$ of Group A patients who received physostigmine and in 14 per cent (6/44) of controls. The pattern was similar in Group B. Restlessness was observed in 29 per cent (4/14) of Group B patients who received physostigmine and in 15 per cent (2/13) of controls.

A summary of data collected by questionnaire on the day following anaesthesia is presented in Table VIII.

Dreams. Physostigmine did not produce significant differences in the incidence of dream- 
ing during anaesthesia and recovery. In Group $A$, 62 per cent (23/37) of patients who received physostigmine experienced dreams. Sixty-one per cent of these (14/23), i.e. 38 per cent of the total population, described their dreams as unpleasant. Sixty-four per cent (27/42) of Group A controls experienced dreams. Forty-four per cent $(12 / 27)$ or 29 per cent of the population described their dreams as unpleasant.

The pattern was similar in Group B. Sixtyseven per cent $(8 / 12)$ of the physostigmine group dreamed. In 75 per cent $(6 / 8,50$ per cent of the population) the dreams were unpleasant. Seventy-five per cent $(9 / 12)$ of Group B controls experienced dreams of which 22 per cent $(2 / 9,17$ per cent of the population) were unpleasant.

The incidence of nausea, vomiting and dizziness experienced after anaesthesia was high in both groups and comparable in control and experimental populations (Table VIII).

Subjects were not observed systematically for signs of increased cholinergic activity with the exception of the cardiovascular system. One patient in Group B developed a transient bradycardia, rate 44,2 to 3 minutes after physostigmine. No treatment was required. Excessive sweating and salivation were noted in a small number of patients. The latter was not of consequence in terms of the patients' spontaneous maintenance of a clear airway.

\section{Discussion}

Opiate or opiate-hyoscine combinations have been found by some to be optimum premedication for ketamine anaesthesia. ${ }^{2.14}$ We administered Pantopon but excluded hyoscine because of the established effect of physostigmine on the postoperative somnolence caused by hyoscine. ${ }^{23.24}$ Atropine was included, however, because excess salivation has been found by some to be troublesome during ketamine anaesthesia and because bradycardia has been observed during dilatation of the cervix in patients who did not receive anti-cholinergics before dilatation and curettage under ketamine anaesthesia. ${ }^{\text {is }}$ In the dose employed, atropine should rarely produce somnolence or behavioural abnormality. ${ }^{25}$

Myriad combinations of opiates, hypnotics, tranquillizers and anti-cholinergics administered before or after ketamine have been evaluated in attempts to reduce or eliminate the various psychic sequelae of ketamine anaesthesia. 3,5.6.14-17 Because no regimen has consistently reduced sequelae in adults to levels acceptable to patients and physicians, the use of ketamine has been restricted in general to paediatric practice and to special circumstances in adult anaesthesia where the advantages justify the disadvantages.

The brief report by Balmer ${ }^{20}$ appeared to provide a means of broadening the usefulness of ketamine. It seemed possible that physostigmine might antagonize ketamine. While ketamine lacks the anti-cholinergic properties common to the majority of agents antagonized by physostigmine, the effectiveness of physostigmine as an antidote to drugs without known anti-cholinergic activity, such as diazepam, ${ }^{19}$ ethclorvinyl (Placidyl), methyprylon (Noludar) ${ }^{27}$ and halothane ${ }^{2 B}$ has been demonstrated. Animal studies have provided additional information suggestive of a role for physostigmine as a ketamine antagonist. Albin, et al. ${ }^{21}$ noted the attenuation of postoperative delirium and a decreased recovery time in dogs given a potent cholinesterase inhibitor either before or after an anaesthetic dose of ketamine. Winters and Kolt ${ }^{22}$ demonstrated that the behavioural and electroencephalographic manifestations of ketamine anaesthesia in cats could be prevented by pretreatment with physostigmine.

Accordingly, we studied 111 patients who had undergone ketamine anaesthesia for therapeutic abortion by dilatation and suction curettage. The results of this study, however, do not demonstrate improvement of any aspect of the postoperative course of patients who received physostigmine after ketamine anaesthesia. In fact, patients who received physostigmine immediately upon conclusion of the operative procedure had delayed recovery of consciousness and orientation and spent longer periods in the recovery room than controls. By contrast, patients in whom administration of physostigmine was delayed until 30 minutes after the last ketamine dose (Group B) did not demonstrate delayed recovery as measured by our criteria. It seems unlikely that prolongation of recovery of consciousness and orientation was the effect of physostigmine per se because comparable increases were not seen in Group B patients who were in advanced stages of recovery (See Table V) when physostigmine was administered. The prolonged recovery of orientation and consciousness in Group A patients who received physostigmine raises the possibility of a synergism of effect between ketamine and physostigmine. Current knowledge of the pharmacology of ketamine and physostigmine does not provide an 
explanation for such an effect. As a cholinesterase inhibitor physostigmine might be expected to enhance the effect of drugs acting through cholinergic mechanisms; but cholinergic activity has not been attributed to ketamine. Our results suggest the possibility that the neurotransmitter acetylcholine may prove to be a mediator of the activity of ketamine.

The explanation of the synergism which these results imply might, on the other hand, lie with hitherto unidentified effects of physostigmine. Physostigmine is viewed as a cholinergic drug. However, its effectiveness as an antidote to agents without established anti-cholinergic activity ${ }^{19.27 .28}$ has prompted suggestions that it has non-specific analeptic activity. "It does appear likely that ketamine produces its "dissociative" anaesthetic effect by central nervous system excitation at subcortical levels rather than by depression. ${ }^{29.30}$ In this light, the apparent potentiation of ketamine by physostigmine may be more readily understandable.

Our results contradict those of Balmer ${ }^{20}$ who found physostigmine effective in reversing ketamine-induced somnolence, His studies evolved from experience in a somnolent patient who had received diazepam, droperidol and ketamine. The patient awakened promptly after physostigmine administration. Residual analgesia was noted and, since no agent with analgesic effects other than ketamine had been given, he concluded that the sedative effects of ketamine had been reversed. It has been established that the analgesic action of ketamine is more prolonged than the soporific effects ${ }^{31}$ and it seems likely that his patient awakened because of the reversal of the sedative effects of diazepam and droperidol rather than of ketamine.

Physostigmine salicylate was of no benefit in reducing emergence reactions defined here as restlessness or hallucinatory behaviour apparent to recovery room observers. The incidence was 26 per cent among physostigmine-treated patients and 21 per cent among controls. The $23 \mathrm{per}$ cent rate for the total population $(26 / 111)$ is remarkably similar to the 24 per cent incidence of emergence reactions noted by Sussman ${ }^{8}$ in a more heterogenous population of patients over 16 years of age. The absence of hallucinations in Group B patients is noteworthy. These patients were not undergoing repeated assessment during the early portion of the recovery room stay and the apparent reduction of hallucinations may be the result of decreased afferent stimuli during early awakening. The implication for recovery room management of ketamine patients is obvious and has been suggested previously. ${ }^{32}$ However, the limitations created by the nature of the recovery room environment and the necessity to monitor vital signs makes effective reduction of afferent stimuli difficult and impractical.

Similarly, physostigmine did not decrease the incidence of dreams (Table VII). Sixly-three per cent $(31 / 49)$ of patients treated with physostigmine and 67 per cent (36/54) of controls dreamed. The overall incidence of dreams, 65 per cent, parallels the 60 per cent rate noted by Krestow ${ }^{7}$ in a study of dreams after ketamine anaesthesia for therapeutic abortion. The 33 per cent incidence of unpleasant dreams in the total population is also similar to the observed 38 per cent rate in Krestow's study. Unpleasant dreams were somewhat, though not significantly, more frequent in the groups treated with physostigmine (41 per cent) than in controls ( 26 per cent).

Nausea and vomiting occurred in 75 to 90 per cent of patients in the various experimental groups, the incidence being slightly but not significantly higher in those who received physostigmine. This frequency of nausea and vomiting is unacceptably high. Improvement might be anticipated with the use of premedicants with anti-emetic actjvity, such as hyoscine. promethazine and droperidol.

The results we have obtained do not justify the use of physostigmine salicylate as a ketamine antidote. We conclude, in fact, that when administered in the early stages of spontaneous recovery from the anaesthetic effects of ketamine, physostigmine is in some way synergistic with ketamine and will prolong recovery of orientation and consciousness. In addition, physostigmine administered after ketamine anaesthesia does not decrease the incidence of emergence phenomena measured either objectively or subjectively. In our hands ketamine remains an agent which is useful in paediatric practice and in special circumstances in adult anaesthesia where its advantages during operation outweigh the disadvantages of the recovery phase.

\section{SUMMARY}

One hundred and eleven patients undergoing ketamine anaesthesia for therapeutic abortion were studied in a double-blind trial of the reversal of ketamine by physostigmine administered postoperatively. The results demonstrate that physostigmine does not shorten recovery time or reduce the occurrence of ketamine emergence 
phenomena such as hallucinations, restlessness and dreams. In fact. the recovery course was prolonged in patients given physostigmine immediately upon termination of anaesthesia as compared with controls. By contrast, when physostigmine was given 30 minutes after the last dose of ketamine, the recovery was not prolonged as compared with that of the placebotreated controls. These findings suggest some synergism between the effects of ketamine and physostigmine and should discourage the use of physostigmine as a ketamine antidote.

\section{RÉSUMÉ}

Cette étude à double insu porte sur ce renversement de la kétamine par la physostigmine administrée pendant la période post-opératoire à cent onze patientes anesthésiées pour un avortement thérapeutique. Les résultats montrent que la physostigmine ne raccourcit pas le temps de récupération ni ne diminue l'incidence des phénomènes d'émergence associés à la kètamine (hallucinations, agitation, rêves). En réalité, la récupération des patientes qui avaient reçu de la physostigmine immédiatement après l'anesthésie fut prolongée comparativement aux contrôles. Par contre, si la physostigmine était administrée 30 minutes après la dernière dose de kétamine, la récupération ne s*est pas prolongée en comparaison avec les patientes qui avaient reçu un placebo. Ces résultats laissant supposer l'existence de synergisme entre les effects de la kétamine et de la physostigmine et devraient décourager l'usage de la physostigmine comme antidote de la kétamine.

\section{ACKNOWLEDGEMENTS}

The authors wish to thank the gynaecologists of Toronto General Hospital for permitting the participation of their patients. As ever, we are grateful to the Recovery Room nurses for their patience and vigilance.

\section{ReFERENCES}

I. Dundee, J.W. Bovile, J.G., Clarke, R.S.J. \& Pandir, S.K. Problems with ketamine in adults. Anaesthesia 26: 86 (1971).

2. Morgan, M., Loh, L., Singer, L. \& Moore, P.H. Ketamine as the sole anaesthetic agent for minor surgical procedures. Anaesthesia 26: 158-165 (1971).

3. Sadove, M.S., Hatano. S., Zahed, B., Reduin, T., ARAstounejad, P. \& Roman. V. Clinical study in the prevention of the side effects of ketamine anesthesia. Anesth. Anatg. Curr. Res. 50: 388-393 (1971).

4. Hervey, W.H. \& Hustead. R.F. Ketamine for dilation and curettage procedures: patient acceptance. Anesth. Analg. Curr. Res. 5I: 647-652 (1972).

5. Loh, L. Singer, L., Morgan, M. \& Moore, P.H. Influence of diazepam on the emergence reactions following ketamine anaesthesia. Can. Anaes. Soc. J. 19: 421-425 (1972)

6. Agajian, J.C. Page, P. \& Morgan, M. Effects of droperidol and nitrazepam on emergence reactions following ketamine anesthesia. Anesth. Analg. Curr. Res, 52: 385-389 (1973).

7. Krestow, M. The effect of post-anaesthetic dreaming on patient acceptance of ketamine anaesthesia: a comparison with thiopentonenitrous oxide anuesthesia. Can. Anues. Soc. J. 2I: 385-389 (1974).

8. SUSSMAN, D.R. A comparative evaluation of ketamine anesthesia in children and adults. Anesthesiology 5: 459-464 (1974).

9. DundeE, J.W. \& WYANT, G.M. Intravenous anaesthesia. Ist Ed. Edinburgh and London: Churchill Livingstone, p. 229 (1974).

10. Corssen, G. \& Domino, E.F. Dissuciative anesthesia: further pharmacologic studies and first clinical experience with the phencyclidine derivative CI-581. Anesth. Analg. Curr. Res. 45: 29-40 (1966).

11. BeTTS, K.B. \& PARKER, C.E. Use of ketamine in an asthmatic child: a case report. Anesth. Analg. Curr. Res. S0: 420-421 (1971).

12. Corssen, G.. Gutierrez, J., Reves, J.G. \& Huber, F.C. Ketamine in anesthetic management of asthmatic patients. Anesth. Analg. Curr. Res. $51: 588-596(1972)$.

13. Galloon. S. Ketamine for obstetric delivery. Anesthesiology 44: 522-524 (1976).

14. Bovill, J.G., Clarke, R.S.J., Dundee, J.W., Pandit, S.K. \& Moore, G. Clinical studies of induction agents. XXXVIII: effect of premedicants and supplements on ketamine anaesthesia. Brit. J. Anaesth. 43: 600-608 (1971).

15. Galloon, S. Ketamine for dilatation and curettage. Can. Anaes. Soc. J. 18: 600-613 (1971).

16. JoHNSTONE. M. The prevention of ketamine dreams. Anaesth. Intensive Care $1: 70-74$ (1972).

17. Collier, B.B. Premedication and ketamine. Anaesthesia 28: 194-196 (1973).

18. Heua, P. \& Galloon, S. A consideration of ketamine dreams. Can. Anaes. Soc. J. 22: 100-105 (1975).

19. Murdoch, J.K. Physostigmine salicylate - a drug literature review. Can. J. Hosp. Pharm. 29: $117-118(1976)$

20. BaLMER, H.G.R. The reversal of ketamine sedation by physostigmine. Proc. Sixth World Congress of Anaesthesiology, April 24-30. Mexico City. pp. 222-223 (1976)

21. Albin, M.S., Bunegin, L., Massopust, L.C. \& JANNETTA, P.J. Ketamine-induced post-anesthetic delirium attenuated by tetrahydroaminoacridine. ExptI. Neurol. 44: 126-129 (1974).

22. WINTERS, W.D. Kotr, K.S. Neuropharmacological interactions between ketamine and 
physostigmine, diazepam or propanolol. Proc. West Pharmacol. Soc. 19: 232-236 (1976).

23. Greene, L.T. Physostigmine treatment of anticholinergic drug depression in postoperative patients. Anesth. Analg. Curr. Res. 50: 222-226 (1971).

24. Brebner, J. \& Hadley, L. Experiences with physostigmine in the reversal of adverse postanaesthetic effects. Can. Anaes. Soc. J. 23: 574-581 (1976).

25. LoNGo, V.G. Behavioural and electroencephalographic effects of atropine and related compounds. Pharmacol. Rev. 18: 965-966 (1966).

26. Crowell, E.B. \& Ketchum, J.S. The treatment of scopolamine-induced delirium with physostigmine. Clin. Pharmacol. Ther. 8: 409-414 (1967).

27. Natel, S., Bayne, L. \& Ruedy, J. The (non) specificily of physostignine in drug overdose. Annals of the Royal Coll. Phys. Surg. Can. 11:36 (1978).

28. Hill, G.E., Stanley, T.H. \& Sentker, C.R.
Physostigmine reversal of postoperative somnolence. Can. Anaes. Soc. J. 24: 707-711 (1977).

29. Ferrer-Allado, T. Brechner, V.L.. Dymond, A., Cozen. H. \& Crandall, P. Ketamineinduced electroconvulsive phenomena in the human limbic and thalamic regions. Anesthesiology 38: 333-344 (1973).

30. Winters, W.D. Ferrer-Allado. T.. GuzmanFlores, C. \& Alcarez, M. The cataleptic state induced by ketamine: a review of the neuropharmacology of anesthesia. Neuropharmacology 11 : 303-315 (1972).

31. TeuteberG, H.W. \& Nolte, H. Ketamina, um novo anestesico venoso com propriedada analgesica elevada. Rev. Brasil. Anest. 19: 459-469 (1969).

32. Corssen, G., Mirasaka, M. \& Domino, E.F. Changing concepts in pain control during surgery: dissociative anesthesia with $\mathrm{Cl}-581$. A progress report. Anesth. Analg. Curr, Res. 47: 746-759 (1968). 